\title{
Macro Stress Testing in the Banking System of China
}

\section{Bo Jiang}

received his $\mathrm{PhD}$ in Economics from the Nottingham Business School, Nottingham Trent University in 2015. His research work has focused on financial stability, both in the UK and in the China. His research uses econometrics analysis of time series data and panel data.

\section{Bruce Philp}

is presently the Head of Research and Enterprise at Birmingham City University Business School. He obtained his PhD from the University of Manchester in 2001 and since then has published in a number of academic journals, principally in the macroeconomic study of income distribution and crisis. He is an editorial board member for Review of Political Economy, and Economic Issues.

\section{Zhongmin Wu}

is Reader in Economics in Nottingham Business School. He received his $\mathrm{PhD}$ in Economics from the University of Southampton in 2001. He was former president of the Chinese Economic Association in the UK (2007-2008), and currently board member. His research work mainly uses econometric analysis of panel data. He has published in 
Journals such as Economics Letters, Industrial Relations Journal, Journal of Development Studies, Regional Studies, Applied Economics, China Economic Review, Journal of Economic Studies, North American Journal of Economics and Finance, etc. He edited two books, both published by Routledge in 2009 .

Correspondence: Dr Zhongmin Wu, Nottingham Trent University, 50 Shakespeare Street, Nottingham NG1 4FQ, UK

\section{ABSTRACT}

In this paper we develop a framework for macro stress testing of China's banking system. Our estimates of the correlations between banks' stability indicators and macroeconomic factors establish significant relationships between the non-performing loan ratio and key macroeconomic variables, such as GDP growth, the retail price index (RPI), the unemployment rate, total fixed investment, the money supply, interest rates, and exchange rates. Further, results from the macro stress tests show that robustness, or otherwise, of the banking system is highly dependent on the source of the potential risk. Our value-at-risk tests suggest that (at a 99\% confidence level) the Chinese banking system is robust with respect to interest rate shocks. However, GDP growth and exchange rate shocks exhibit a profound negative effect, indicating that significant losses become likely. These results should inform investors, policy-makers and regulators with regard to loss-limitation in China's banking system. 
JEL CODES: C15; E58; E44; G21

KEY WORDS: China; Macro stress testing; Non-performing loan; VAR analysis

\section{INTRODUCTION}

In recent years banks have engaged in increasingly complex and diverse international financial activities. The role of banks, as one of the most important financial intermediaries in an economy, and as a prerequisite for sustainable economic growth, reinforces the fact that instability in the banking system would be costly for the real economy. This is manifest by the myriad ways the current Global Financial Crisis (GFC) has impacted economies (e.g. Tagkalakis, 2013; Aboody et al., 2014). ${ }^{1,2}$ In particular, the costs and losses, at the national level, associated with failures within the banking system, underscore the need for supervision with a macro-prudential perspective, particularly with regard to how banks measure and control their risk exposure.

From the macro-prudential perspective, the Basel III Accord emphasized the need for the development of a more robust stress-testing approach compared to Basel II. ${ }^{3-6}$ The emphasis suggests that up-to-date risk management techniques — particularly, 'macro stress-testing' — have become effective tools in assessing stability of the banking system, and the financial system more broadly (see Sorge, 2004). ${ }^{7}$ This is especially so from the perspective of central banks, where stress tests are a prudent technique alongside the traditional regulation methods used to assess risk exposure in the financial system (Marcelo et al., 2008). ${ }^{8}$ 
In this paper we focus on macro stress testing in assessing financial stability in China, and we address two questions that naturally arise. First, how should we measure the potential risks in the banking system? Secondly, how do we quantify the vulnerability of the banking system to potential risks? To achieve answers to these, we develop a framework for macro stress testing of credit exposures in the Chinese banking system. Our empirical analysis adopts a vector autoregression (VAR) approach, and investigates the relationship between the ratio of nonperforming bank loans and key macroeconomic factors, such as GDP growth, RPI, the unemployment rate, fixed investment, real estate price indexes, the money supply, interest rates, and the exchange rate. Macro stress testing assesses the credit risk of banks' overall loan portfolios and mortgage exposures by mapping multivariate scenarios against potential risks. The test introduces different types of macroeconomic shocks into the scenarios, which are designed to replicate those that have occurred in past financial crises and stochastic simulations.

The present study is thus predicated on the following: first, stress-testing has become an integral part of banks' risk management assessments; second, in interpreting the results of stress tests, many banks create a link between market shocks and banks' responses. Interestingly, in China, which is an emergent global economy, stress testing is still at the embryonic stage. On this basis, we posit that the analysis contained herein is timely and contributes to our understanding of this very important emerging market economy.

\section{BACKGROUND}


Previous literature and the experience of the GFC has shown that many financial institutions can experience large losses. Stulz $(2008)^{9}$ argues that a large loss is not necessarily a consequence of risk-management failure, because large losses can happen even if risk management is stringent. In other words, the common task of daily risk management cannot completely rule out extreme exposure to losses. This notwithstanding, the recent GFC has also highlighted serious deficiencies in traditional risk management models (e.g. Huang et al., 2009; Aizenman et al., 2012) $)^{10,11}$ and underscores the necessity for improvements in risk management systems, and the adoption of improved risk-management measures to better depict the possible risks. This is why stress tests and scenario analysis are apposite.

Moreover, regulators need to provide a clearer definition of financial stability and the framework to achieve this goal. Recently, regulators have charged banks with the responsibility of ensuring a sound, stable and efficient banking system as a whole, i.e. financial stability, rather than only assuring the soundness of their own bank (Borio, 2006). ${ }^{12}$ Financial stability depends, in essence, on the prudential regulation and effective supervision which was instituted in 1999 by the IMF and the World Bank via the Financial Sector Assessment Program (FSAP). Although there is no single generally accepted definition of financial stability, Marcelo et al. suggest that 'for a given economy, [financial stability] provides sufficient assurance that the efficiency of intermediation between the suppliers and demanders of funds (broadly speaking, between investors and savers) will not be significantly affected by adverse events (shocks)' (2008, p.65). ${ }^{8}$ Given the huge negative implications for the real economy in the event of financial instability, regulatory authorities should have a particular and well-justified interest in 
ensuring financial stability (as highlighted by the Basel III Accord).

As a result of the widespread implementation of the FSAP, stress tests are now broadly utilized. According to Borio et al. (2012), ${ }^{13}$ micro and macro stress tests have four elements: the risk exposures subjected to stress; the scenario defining the shocks; the model mapping the shocks onto an outcome; and, the measure of the outcome. More specifically, the aim of stress testing is to measure the impact of severe shocks which are potentially able to harm financial stability. Hence, the results of stress testing are threefold: to add value to the internal control exercised by banks in the course of risk management; to serve as a basis for fostering prudential techniques of protection against adverse situations; and, to facilitate prevention, early warning and response tasks to deal with these adverse situations (see Marcelo et al. 2008). ${ }^{8}$

As pointed out by Drehmann (2005), ${ }^{14}$ stress testing models differ in terms of complexity and the risks considered. Despite many significant contributions to stress testing (e.g.: Elsinger et al., 2006; Jacobson et al.,2005; De Graeve et al., 2008; Pesaranet al.,2009; Aikman et al., 2009), ${ }^{15-19}$ there is no consensus on the set of tools, or the best approach, to use. As a consequence of this various approaches have been proposed, including Wilson (1997a, 1997b), ${ }^{20,21}$ Virolainen (2004), ${ }^{22}$ Sorge and Virolainen (2006), ${ }^{23}$ Misina et al. (2006), ${ }^{24}$ and Jimenez and Mencia (2009). ${ }^{25}$ Differences notwithstanding, the underlying structures assume a linear relationship between macroeconomic variables and the probability of default on the bank's loan portfolio.

Studies specific to China are sparser. Xu and Liu $(2008)^{26}$ compare several popular macro 
stress testing approaches and focus on the use of macro stress testing to estimate the stability of the financial system. Using a logit model, Ren and Sun $(2007)^{27}$ estimate credit risk in the banking industry. For their part, Chen and Wu $(2004)^{28}$ empirically investigate vulnerability of China's banking system over the period 1978-2000. They uncover evidence to suggest that macroeconomic dynamics affect the bank's stability via macroeconomic policies.

\section{METHODOLOGY}

In testing credit risk exposure in China's banking system, we will begin by adopting the framework proposed by Wilson (1997a, 1997b), ${ }^{20,21}$ Boss (2002) ${ }^{29}$ and Virolainen (2004) ${ }^{22}$, i.e. estimating the relationship between credit risk and macroeconomic dynamics. Next, we employ the Monte Carlo simulation approach to examine the distribution of possible default rates for the scenario under investigation.

We define $N P L R_{t}$ as the aggregate non-performing loan ratio of the whole banking system in China in period $t$. Since $0 \leq N P L R_{t} \leq 1$ we can employ its logit-transformed value $\left(y_{t}\right)$ instead of $p_{t}$ as the dependent variable.That is

$$
y_{t}=\ln \left\{\frac{1-N P L R_{t}}{N P L R_{t}}\right\}
$$

After this canonical processing for the credit risk index (note here that $-\infty<y_{t}<+\infty$ ), it follows that the $N P L R_{t}$ is negatively related to $y_{t}$, which means a higher $y_{t}$ indicates a better creditrisk status, and vice versa. Further, preliminary (augmented Dickey-Fuller) unit-root tests with 
the time trend and the intercept finds $y_{t}$ (our dependent variable) to be stationary. More specifically, $y_{t}$ dependents on its lags, and the $n$ lagged values of the macroeconomic variables:

$$
y_{t}=\alpha+A_{1} x_{t-1} \cdots+A_{n} x_{t-n}+B_{1} y_{t-1} \cdots+B_{n} y_{t-n}+\mathrm{v}_{t}
$$

where $y_{t}$ is a vector of endogenous variables and $x_{t}$ is a vector of exogenous variables. In this equation $\alpha$ is the vector of intercepts and $A_{1} \cdots A_{n}$ are matrices of coefficients on the macroeconomic variable lagged $n$ times. The matrices of coefficients $B_{1} \cdots B_{n}$ are associated with the lags on the dependent variable, and the disturbance term is given $\operatorname{byv}_{t}$, which may be contemporaneously correlated but are uncorrelated with their own lagged values and uncorrelated with all of the right-hand side variables.

This macro-economic framework examines the dynamics of the macro-economic variables as well. Based on Wilson's (1997a, 1997b), ${ }^{20,21}$ original specification, which every macroeconomic variable follows an autoregressive (AR) process, we generalize a more realistic dynamic process by adopting by the following specification:

$$
x_{t}=\beta+C_{1} x_{t-1} \cdots+C_{n} x_{t-n}+D_{1} y_{t-1} \cdots+D_{n} y_{t-n}+\varepsilon_{t}
$$

where $\beta$ is the vector of intercepts; $C_{1} \cdots C_{n}$ and $D_{1} \cdots D_{n}$ are coefficient matrices; and $\varepsilon_{t}$ is a vector of disturbances. Following Wong et al. $(2006)^{30}$ we recognize that macro-economic variables are mutually interdependent and equation (2) explicitly accounts for feedback effects of bank performances on the economy (the terms $D_{1} y_{t-1} \cdots+D_{n} y_{t-n}$ ). Equation (1) and (2) together compose the framework to study the economic performance and the associated 
financial stability indicators.

In developing our model we aim to improve on the specification employed in Virolainen $(2004)^{22}$ and Wilson (1997a, 1997b). ${ }^{20,21}$ First, we employ a lag-effect of the macroeconomic variables to banks' credit risk. Second, by allowing $x_{t}$ to depend on $y_{t-1}, y_{t-s}$ this implies previous bank performances can influence the present macro economy.

Subsequently, we employ Monte Carlo simulations to generate the distribution of possible credit losses under the macroeconomic shock scenarios, which we can then compare with possible credit losses under the baseline scenario. Nevertheless, it is instructive to note that this approach has some limitations, such as the treatment of the contagion effect within the banking system. First, it is not unusual for central banks to use aggregate data when testing the change of credit risk in the regional banking system, based on the assumption that we move from top to bottom. However, the use of aggregate data when assessing credit risk in the whole banking system is equivalent to conducting micro stress testing with the aggregate data, and ignoring the structural problems within the financial system. Second, the adaptive response of banking institutions may generate a feedback effect. It is commonplace that in a number of the macro stress testing practices the initial shock effect from the macro economy to the banking system is small in the first period, while the risk effect will be significantly increased when the period of stress testing is prolonged. In other words, the change of risk factors in the first round should not be treated as the ultimate outcome and underscores the need to continually reassess the response behavior of the banking system to a (macroeconomic) shock. 


\section{EMPIRICAL RESULTS AND DISCUSSION}

\subsection{Variables description and data sources}

Following the framework discussed above, we adopt a macroeconomic credit risk model to estimate the relationship between macroeconomic variables and the non-performing loan ratio (NPLR) of the banking system covering the period from 2000Q1 to 2012Q3. Due to the importance of selecting the appropriate variables, Table 1 presents a brief summary of the variables considered in previous research, which then informs our choice of variables for China. Based on the aims of this research (and the reliability and availability of data), we will focus on eight major explanatory variables for China (see Table 2).

Table 1: Summary of Macroeconomic variables employed in previous research

$\begin{array}{lll}\text { Author(s) } & \text { Geographical } & \text { Macro variables } \\ \text { Location } & \\ \text { Wong et al. (2006) })^{30} \quad \text { Hong Kong } & \text { Real GDP growth; Real GDP growth of Mainland } \\ & \text { China; Real interest rates (HIBOR); Real property } \\ & \\ \text { Bardsen } \text { et } \text { al. } & \text { prices. } \\ & \text { Norway } & \text { Real GDP; Real household consumption; } \\ & \end{array}$


$(2006)^{31}$

Bunn et al. $\quad(2005)^{32} \quad$ United Kingdom $\quad$ Interest rate; GDP; Output gap; Unemployment rate;

Misina et al. (2006) $)^{24}$ Canada

Virolainen (2004) $)^{22} \quad$ Finland prices.

Real exchange rate; Inflation rate; House price inflation

rate.

GDP growth rate; Unemployment rate; Interest rate;

Credit/GDP ratio.

Nominal GDP growth; Interest rate; Exchange rate;

M2; International balance of payment; Asset price.

We identify three popular dependent variables typically considered in previous research, namely: the firm's probabilities of default (PD) (see for example, Pesaran et al., 2006); ${ }^{33}$ corporate expected default frequencies (EDF) (see for example, Alves, 2005); ${ }^{34}$ and, the balance sheet information of the bank (such as NPLR, capital adequacy ratios and liquidity). Compared to PD and EDFs, balance sheet information is a traditional measurement, but it is limited because balance sheet information is only available on a relatively low-frequency basis (quarterly and yearly). In contrast, the PD and EDF are available at a higher frequency, and they can be forward-looking. Due to the nature of China's commercial banks, and the availability of relevant data, we employ NPLR as the measurable dependent variable pertaining to the balance sheet. According to the Loan Quality Assessment Guidelines (China Bank Regulatory Commission, 2005), ${ }^{35}$ the NPLR is classified as the total of sub-loans, doubtful- 
loans and loss-loans divided by total loans. In other words, a higher NPLR implies a higher level of credit exposure.

Table 2: Variable list

\begin{tabular}{|l|l|}
\hline Variable & Description \\
\hline NPLR & Non-performing Loan Ratio \\
\hline GDP & Nominal Gross Domestic Product Growth Rate \\
\hline RPI & Retail Price Index \\
\hline UNE & Unemployment Rate \\
\hline HPI & House Price Index \\
\hline FIX & Total Fixed Investment, nominal (\% YOY) \\
\hline M2 & Money Supply, M2 (\% YOY) \\
\hline INT & Interest Rate \\
\hline EX & Exchange rate, Chinese Yuan to US Dollar \\
\hline
\end{tabular}

The eight explanatory macroeconomic variables (Table 2), including the GDP growth rate, the retail price index, the unemployment rate, a house price index, the money supply (M2), the 
interest rate, exchange rate, and total fixed investment, can be placed into four categories to capture different kinds of potential shocks:

1. The business cycle is measured by GDP growth, retail price index (for inflation), and the unemployment rate, as the stability of the macro-economy is the goal of a healthy financial system. A growing economy is likely to be associated with rising incomes and reduced financial distress. Therefore, GDP growth is negatively associated with the NPLR and unemployment is positively related with the NPLR. After maintaining high-growth for a number of years, the growth of China's economy has slowed down somewhat, while inflation remains above the Government's target. Thus, policymakers in China have been concerned with how to implement a successful "softlanding", whilst dealing with inflation.

2. Credit risk is measured by the interest rate, money supply (M2), and total fixed investment. Banks are still the major source of corporate and fixed investment in China, and the interest rate and credit quota have a direct impact on the credit exposure of the banks' balance sheets. Otherwise, unlike their counterparts in developed countries, income from loans surprisingly makes more than 80 percent of the total profit of commercial banks in China. A hike in interest rates weakens borrowers' debt servicing capacity, thus, NPLR is expected to be positively related with the interest rate.

3. Property-value bubbles, which are measured by house price indexes, have triggered several financial crises, such as the Florida property bubble in late 1920s (White, 2009), 
${ }^{36}$ the depression of Japan since 1991 (Posen, 2003), ${ }^{37}$ and the subprime lending crisis since March 2008. In China, the loans to the real estate sector have grown to RMB 11.74 trillion in September 2012, an increase of approximately $12.1 \%$ since the end of 2011 (Source: China Banking Regulatory Commission). Should this indicate a bubble this may create problems since real estate is a major item of collateral, and banks would be unwilling to service the debt should the value of real estate decline.

4. Exchange rate risk is measured by the exchange rate (Chinese Yuan to US Dollar), which reflects the global macroeconomic environment. The fluctuation of the exchange rate might significantly affect the stability of the whole economy and output. An appreciation of the exchange rate can have mixed implications. On the one hand, it could weaken the competitiveness of export-oriented firms and adversely affect their ability to service their debt. On the other, it can improve the debt-servicing capacity of borrowers who borrow in foreign currency.

These variables are initially chosen as macroeconomic factors by the R-squared values of the regressions. We have also tried some other macroeconomic variables like the consumer price index, producer price index, and stock market index, but find no additional explanatory power.

We source the NPLR data from the China Banking Regulatory Commission website and the Ruisi Statistical database. Other data used in this study are sourced from DataStream, the National Bureau of Statistics of China, and The People's Bank of China. The summary descriptive statistics of data are presented in Table 3. 
Table 3: Summary statistics, 2000Q1-2012Q3

\begin{tabular}{|c|c|c|c|c|c|c|c|c|c|}
\hline & NPLR & GDP & RPI & UNE & HPI & FIX & M2 & INT & EX \\
\hline Mean & 11.22 & 9.77 & 1.51 & 4.02 & 4.93 & 19.58 & 12.08 & 6.37 & 7.59 \\
\hline Median & 7.53 & 9.60 & 1.20 & 4.10 & 4.30 & 21.15 & 12.15 & 6.21 & 8.02 \\
\hline Махітum & 29.18 & 14.80 & 7.56 & 4.30 & 12.19 & 37.40 & 19.54 & 7.83 & 8.28 \\
\hline Minimum & 0.90 & 6.60 & -2.03 & 3.10 & -1.10 & 5.39 & 7.07 & 5.76 & 6.29 \\
\hline Std. Dev. & 9.76 & 2.05 & 2.61 & 0.32 & 3.70 & 6.99 & 2.84 & 0.61 & 0.75 \\
\hline Observations & 51 & 51 & 51 & 51 & 51 & 51 & 51 & 51 & 51 \\
\hline
\end{tabular}

Prior to 2000 annual data was only available for some variables. The trend in the NPLR of the banking system in China had climbed to a peak in 1999, thereafter exhibiting a steady decline. In part this turning point may be explained by the establishment of an asset management corporation between 1999 and 2004, which was responsible for managing the bad assets of the four major state-owned commercial banks. Since these "big four" retained in excess of $60 \%$ of the total assets in the whole banking system, the concurrent injection by the Central Bank of a large amount of funds into these "big four" led to the overall NPLR dropping significantly. 
Results of our preliminary tests using the augmented Dickey-Fuller (ADF) method (with trends and intercepts, testing the time series properties for all these variables) suggest that three of the macroeconomic series — specifically RPI, HPI, and M2 - are stationary $I(0)$. The other five variables - i.e. GDP, INT, EX, UNE and FIX — are first order stationary $I$ (1). Because of this we use their first differences, DGDP, DINT, DEX, DUNE and DFIX in the regression.

Table 4: ADF unit root tests

$\begin{array}{lll}\text { Variable } & \text { t-Statistic } & \text { Unit root test result } \\ \text { GDP } & -1.88^{*} & \text { GDP } \sim(1), \text { DGDP } \\ \text { RPI } & -3.67 & \text { RPI } \sim I(0) \\ \text { UNE } & -2.75^{*} & \text { UNE } \sim I(1), \text { DUNE } \\ \text { HPI } & -3.48 & \text { HPI } \sim I(0) \\ \text { FIX } & -0.89^{*} & \text { FIX } \sim I(1), \text { DFIX } \\ \text { M2 } & -7.31 & \\ \text { INT } & -2.69^{*} & \text { M2 } \sim I(0) \\ \text { EX } & -2.12^{*} & \text { INT } \sim I(1), \text { DINT } \\ & & \text { EX } \sim I(1), D E X\end{array}$

* Non-rejection of the null of non-stationarity at $10 \%$ 
Following Lutkepohl $(1993)^{38}$ we focus on the Akaike (AIC), Hannan-Quinn (HQ) and Schwarz (SC) criteria for the selection of the lag lengths in our VAR model. Given the sample size, and the nature of the quarterly data, the results of the Akaike information criterion, Schwarz information criterion, and Hannan-Quinn information criterion all suggest a 4 period lag length (see Appendix).

\subsection{Discussion of results}

In this section we adopt a VAR framework that links the credit risk measurement of the banking system to the macroeconomic variables (outlined in Table 2) which reflect the situation of the macro economy. In our VAR framework we assume that vulnerability in the banking system can be affected by the general economic conditions, and there is a potential feedback effect which allows stress in the banking system to impact the macro economy. Unlike simple linear regression, the order of variables in VAR should be arranged according to the speed of reaction to a particular shock. Therefore, our variable ordering is such that the variables related to the business cycle — such as GDP, RPI and unemployment rate — were located after NPLR, because the business cycle affects the banking system after a lag. Consequently, interest rates and the exchange rate were ordered at the bottom of the VAR.

As the VAR results show in Table 5, most of the signs of the coefficients of the variables are as expected and consistent with other studies (see Wong et al., 2006 $6^{30}$ and Shen and Feng, $\left.2010^{39}\right)$. Thus $y_{t}$ is positively related to the lag effects on GDP growth and the unemployment 
rate due to the fact that when the economy enjoys steady growth with a low unemployment rate, the banking system can share the benefit as the financial intermediary. Meanwhile, $y_{t}$ is negatively related to the lag of RPI and the money supply, albeit via comparatively weak correlations which are below expectation.

Between 2003 and 2007 China's economy experienced a significant cyclical upswing, with vigorous financing demand leading to a tremendous influx of funding into production. The onset of the GFC around 2008Q2 adversely impacted international trade. On the one hand, banks provided more loans to firms to avoid their potential default. On the other hand, the government employed easy monetary policy to ensure smooth growth. As a consequence, default rates remained stable, while the inflation rate and money supply increased significantly.

Table 5: Vector Autoregression Estimates

\begin{tabular}{|c|c|c|c|c|c|c|c|c|c|}
\hline & $y_{t}$ & DGDP & RPI & DUNE & HPI & DFIX & M2 & DINT & DEX \\
\hline \multirow{2}{*}{$\mathrm{y}_{\mathrm{t}}(-1)$} & $0.96^{* * * *}$ & $-4.70 *$ & -2.75 & 0.16 & $-5.63 * *$ & 0.08 & 3.11 & -0.70 & 0.01 \\
\hline & $(-0.27)$ & $(-2.64)$ & $(-2.25)$ & $(-0.12)$ & $(-2.49)$ & $(-9.81)$ & $(-4.18)$ & $(-0.54)$ & $(-0.18)$ \\
\hline \multirow{2}{*}{$\mathrm{y}_{\mathrm{t}}(-2)$} & 0.39 & 2.51 & -2.90 & 0.11 & 3.14 & -0.77 & 1.35 & 0.34 & 0.12 \\
\hline & $(-0.35)$ & $(-3.44)$ & $(-2.93)$ & $(-0.16)$ & $(-3.24)$ & $(-12.81)$ & $(-5.46)$ & $(-0.70)$ & $(-0.23)$ \\
\hline$y_{t}(-3)$ & $-0.66 * *$ & $5.31 *$ & 3.67 & -0.18 & 4.86 & 2.81 & -8.02 & $1.34 * *$ & -0.11 \\
\hline
\end{tabular}




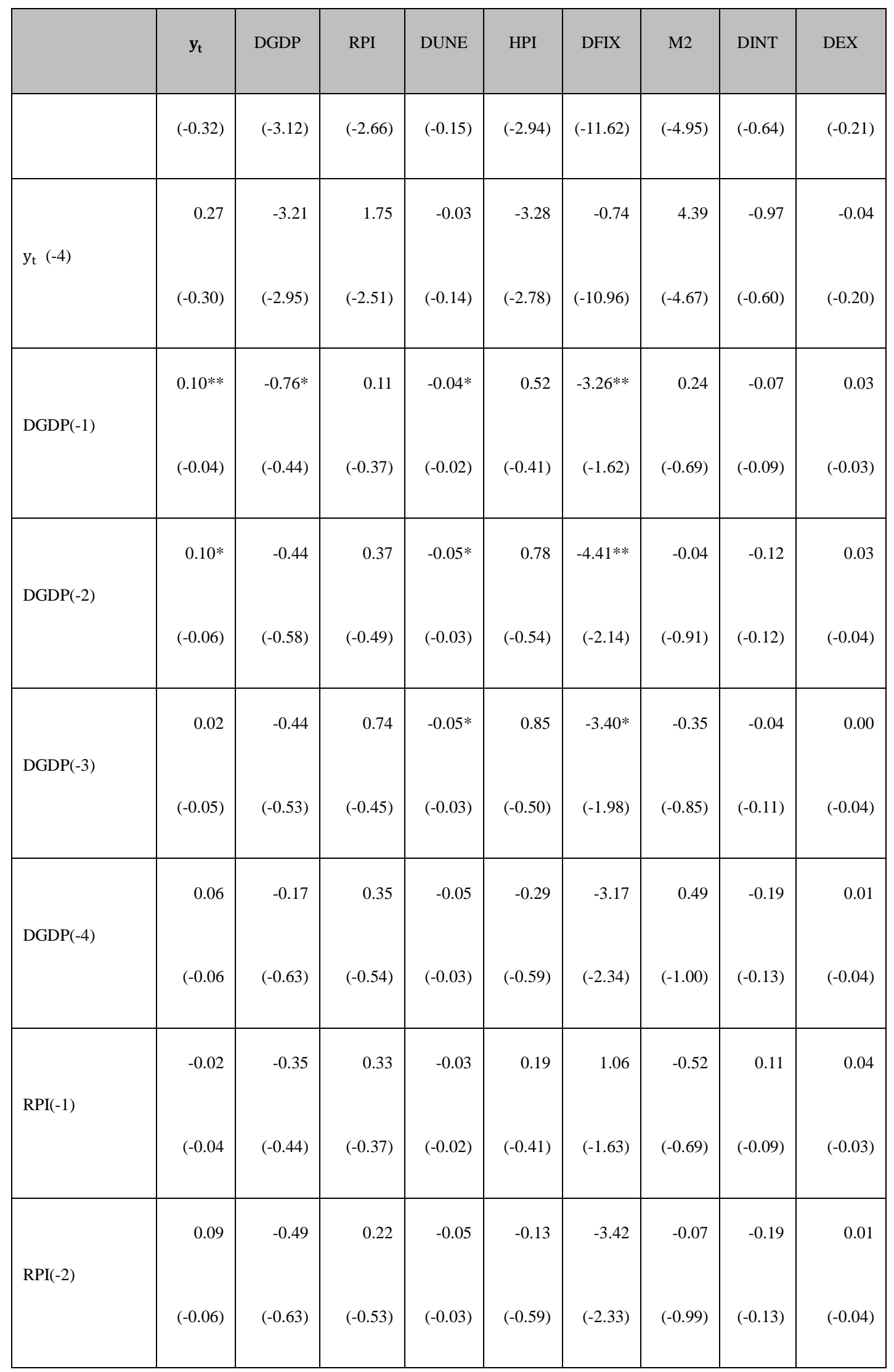




\begin{tabular}{|c|c|c|c|c|c|c|c|c|c|}
\hline & $y_{t}$ & DGDP & RPI & DUNE & HPI & DFIX & M2 & DINT & DEX \\
\hline \multirow{2}{*}{ RPI(-3) } & 0.06 & -0.39 & 0.20 & 0.01 & -0.42 & $-2.89 *$ & 0.13 & -0.06 & 0.03 \\
\hline & $(-0.04$ & $(-0.40)$ & $(-0.34)$ & $(-0.02)$ & $(-0.38)$ & $(-1.49)$ & $(-0.64)$ & $(-0.08)$ & $(-0.03)$ \\
\hline \multirow{2}{*}{ RPI(-4) } & $-0.07 *$ & 0.41 & 0.14 & 0.02 & $0.65^{*}$ & 0.07 & -0.20 & -0.01 & -0.04 \\
\hline & $(-0.04)$ & $(-0.39)$ & $(-0.33)$ & $(-0.02)$ & $(-0.37)$ & $(-1.45)$ & $(-0.62)$ & $(-0.08)$ & $(-0.03)$ \\
\hline \multirow{2}{*}{ DUNE(-1) } & $1.12 * *$ & $-10.48^{*}$ & 1.89 & -0.34 & -3.86 & -19.03 & -3.61 & $-2.08 *$ & 0.11 \\
\hline & $(-0.55)$ & $(-5.42)$ & $(-4.62)$ & $(-0.25)$ & $(-5.11)$ & $(-20.16)$ & $(-8.59)$ & $(-1.10)$ & $(-0.36)$ \\
\hline \multirow{2}{*}{ DUNE(-2) } & $0.83^{*}$ & $-10.30 * *$ & 3.18 & -0.11 & -0.53 & -19.79 & -0.43 & $-2.03 * *$ & -0.09 \\
\hline & $(-0.48)$ & $(-4.69)$ & $(-3.99)$ & $(-0.22)$ & $(-4.41)$ & $(-17.42)$ & $(-7.43)$ & $(-0.95)$ & $(-0.31)$ \\
\hline \multirow{2}{*}{ DUNE(-3) } & $0.82 *$ & $-7.65^{*}$ & 1.57 & -0.13 & -3.65 & -19.70 & -1.93 & $-1.59 *$ & 0.04 \\
\hline & $(-0.44)$ & $(-4.34)$ & $(-3.69)$ & $(-0.20)$ & $(-4.09)$ & $(-16.14)$ & $(-6.88)$ & $(-0.88)$ & $(-0.29)$ \\
\hline \multirow{2}{*}{ DUNE(-4) } & $0.95 * *$ & -2.21 & 2.76 & $0.58 * * *$ & $8.00 * *$ & -9.10 & -3.83 & $-1.40 *$ & -0.02 \\
\hline & $(-0.37)$ & $(-3.61)$ & $(-3.08)$ & $(-0.17)$ & $(-3.40)$ & $(-13.43)$ & $(-5.73)$ & $(-0.74)$ & $(-0.24)$ \\
\hline \multirow{2}{*}{ HPI(-1) } & -0.03 & 0.02 & 0.10 & $0.03 *$ & $0.90^{* * *}$ & 0.89 & -0.13 & 0.00 & -0.02 \\
\hline & $(-0.03)$ & $(-0.30)$ & $(-0.25)$ & $(-0.01)$ & $(-0.28)$ & $(-1.11)$ & $(-0.47)$ & $(-0.06)$ & $(-0.02)$ \\
\hline HPI(-2) & 0.03 & -0.04 & -0.08 & -0.01 & -0.12 & 0.04 & 0.19 & 0.00 & 0.00 \\
\hline
\end{tabular}




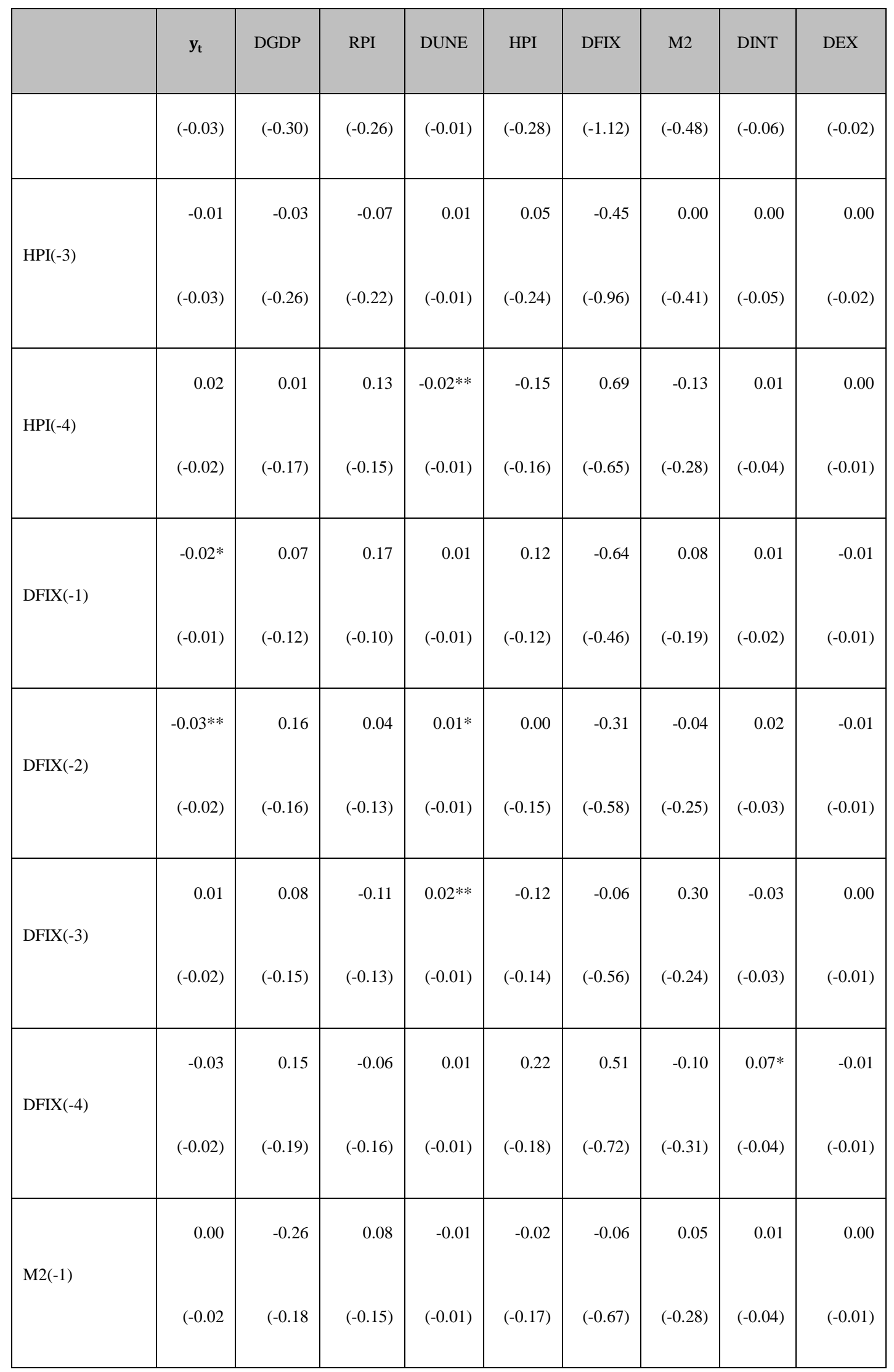




\begin{tabular}{|c|c|c|c|c|c|c|c|c|c|}
\hline & $y_{t}$ & DGDP & RPI & DUNE & HPI & DFIX & M2 & DINT & DEX \\
\hline \multirow{2}{*}{ M2(-2) } & 0.02 & 0.06 & 0.22 & -0.01 & 0.14 & -0.78 & $0.55^{*}$ & -0.05 & 0.01 \\
\hline & $(-0.02)$ & $(-0.19)$ & $(-0.16)$ & $(-0.01)$ & $(-0.18)$ & $(-0.71)$ & $(-0.30)$ & $(-0.04)$ & $(-0.01)$ \\
\hline \multirow{2}{*}{ M2(-3) } & 0.02 & 0.21 & 0.24 & 0.00 & $0.33^{*}$ & -0.32 & 0.36 & -0.02 & -0.01 \\
\hline & $(-0.02)$ & $(-0.18)$ & $(-0.16)$ & $(-0.01)$ & $(-0.17)$ & $(-0.68)$ & $(-0.29)$ & $(-0.04)$ & $(-0.01)$ \\
\hline \multirow{2}{*}{ M2(-4) } & $-0.04 * *$ & 0.20 & 0.09 & 0.01 & 0.13 & 0.16 & -0.43 & $0.06^{*}$ & -0.01 \\
\hline & $(-0.02)$ & $(-0.17)$ & $(-0.15)$ & $(-0.01)$ & $(-0.16)$ & $(-0.64)$ & $(-0.27)$ & $(-0.04)$ & $(-0.01)$ \\
\hline \multirow{2}{*}{ DINT(-1) } & -0.10 & -2.26 & -0.54 & 0.15 & -1.71 & 9.72 & -0.54 & 0.19 & -0.16 \\
\hline & $(-0.22)$ & $(-2.17)$ & $(-1.84)$ & $(-0.10)$ & $(-2.04)$ & $(-8.05)$ & $(-3.43)$ & $(-0.44)$ & $(-0.15)$ \\
\hline \multirow{2}{*}{ DINT(-2) } & 0.14 & -1.40 & -2.10 & $0.17 * *$ & $-2.80 *$ & 2.13 & 2.47 & -0.58 & -0.04 \\
\hline & $(-0.17)$ & $(-1.69)$ & $(-1.44)$ & $(-0.08)$ & $(-1.59)$ & $(-6.28)$ & $(-2.68)$ & $(-0.34)$ & $(-0.11)$ \\
\hline \multirow{2}{*}{ DINT(-3) } & -0.29 & 1.88 & -0.42 & 0.12 & 0.90 & 8.41 & -3.96 & 0.78 & -0.10 \\
\hline & $(-0.22)$ & $(-2.16)$ & $(-1.84)$ & $(-0.10)$ & $(-2.04)$ & $(-8.04)$ & $(-3.43)$ & $(-0.44)$ & $(-0.14)$ \\
\hline \multirow{2}{*}{ DINT(-4) } & $-0.26^{*}$ & -0.79 & -0.65 & $0.11 *$ & -0.83 & 0.39 & 1.15 & 0.10 & -0.04 \\
\hline & $(-0.12$ & $(-1.22)$ & $(-1.04)$ & $(-0.06)$ & $(-1.15)$ & $(-4.55)$ & $(-1.94)$ & $(-0.25)$ & $(-0.08)$ \\
\hline $\operatorname{DEX}(-1)$ & $-1.18^{*}$ & 3.82 & -4.21 & 0.16 & -4.08 & -6.49 & -8.58 & 1.35 & -0.26 \\
\hline
\end{tabular}




\begin{tabular}{|c|c|c|c|c|c|c|c|c|c|}
\hline & $y_{t}$ & DGDP & RPI & DUNE & HPI & DFIX & M2 & DINT & DEX \\
\hline & $(-0.65)$ & $(-6.35)$ & $(-5.41)$ & $(-0.30)$ & $(-5.99)$ & $(-23.63)$ & $(-10.07)$ & $(-1.29)$ & $(-0.43)$ \\
\hline \multirow{2}{*}{$\operatorname{DEX}(-2)$} & $-1.19 *$ & -2.02 & -0.83 & 0.23 & 8.79 & -0.27 & -4.27 & 0.85 & -0.22 \\
\hline & $(-0.69)$ & $(-6.75)$ & $(-5.75)$ & $(-0.32)$ & $(-6.36)$ & $(-25.10)$ & $(-10.70)$ & $(-1.37)$ & $(-0.45)$ \\
\hline \multirow{2}{*}{$\operatorname{DEX}(-3)$} & 0.18 & -2.65 & -2.49 & -0.21 & -7.53 & -35.22 & 10.37 & -0.15 & 0.57 \\
\hline & $(-0.78)$ & $(-7.67)$ & $(-6.53)$ & $(-0.36)$ & $(-7.23)$ & $(-28.53)$ & $(-12.16)$ & $(-1.56)$ & $(-0.51)$ \\
\hline \multirow{2}{*}{$\operatorname{DEX}(-4)$} & -0.01 & 6.50 & 5.43 & 0.17 & 2.49 & -27.69 & -9.97 & -0.52 & 0.31 \\
\hline & $(-0.84)$ & $(-8.21)$ & $(-6.99)$ & $(-0.39)$ & $(-7.74)$ & $(-30.54)$ & $(-13.02)$ & $(-1.67)$ & $(-0.55)$ \\
\hline \multirow{2}{*}{ C } & -0.20 & 0.60 & $-6.33 * * *$ & -0.07 & -2.73 & 8.35 & 4.45 & 0.27 & 0.26 \\
\hline & $(-0.29)$ & $(-2.83)$ & $(-2.41)$ & $(-0.13)$ & $(-2.66)$ & $(-10.52)$ & $(-4.48)$ & $(-0.58)$ & $(-0.19)$ \\
\hline R-squared & 1.00 & 0.86 & 0.98 & 0.90 & 0.99 & 0.78 & 0.92 & 0.88 & 0.78 \\
\hline Adj. R-squared & 0.99 & 0.29 & 0.88 & 0.48 & 0.93 & -0.10 & 0.59 & 0.38 & -0.09 \\
\hline Sum sq. resids & 0.10 & 9.93 & 7.20 & 0.02 & 8.82 & 137.36 & 24.95 & 0.41 & 0.04 \\
\hline S.E. equation & 0.11 & 1.05 & 0.89 & 0.05 & 0.99 & 3.91 & 1.67 & 0.21 & 0.07 \\
\hline F-statistic & 175.12 & 1.52 & 9.88 & 2.14 & 17.05 & 0.89 & 2.77 & 1.76 & 0.90 \\
\hline Log likelihood & 75.12 & -30.02 & -22.62 & 110.75 & -27.27 & -90.43 & -51.20 & 43.21 & 94.30 \\
\hline
\end{tabular}




\begin{tabular}{|l|r|r|r|r|r|r|r|r|r|}
\hline & \multicolumn{1}{|c|}{$\mathbf{y}_{\mathbf{t}}$} & \multicolumn{1}{c|}{ DGDP } & \multicolumn{1}{c|}{ RPI } & DUNE & HPI & DFIX & M2 & DINT & DEX \\
\hline Akaike AIC & -1.66 & 2.91 & 2.59 & -3.21 & 2.79 & 5.54 & 3.83 & -0.27 & -2.49 \\
\hline Schwarz SC & \multicolumn{1}{|c|}{-0.19} & 4.38 & 4.06 & -1.74 & 4.27 & 7.01 & 5.31 & 1.20 & -1.02 \\
\hline Mean dependent & 2.81 & -0.02 & 1.83 & 0.01 & 5.32 & -0.14 & 11.93 & 0.01 & -0.04 \\
\hline S.D. dependent & 1.27 & 1.25 & 2.55 & 0.07 & 3.68 & 3.73 & 2.59 & 0.27 & 0.07 \\
\hline
\end{tabular}

$*, * *$ and $* * *$ indicate significance at the $10 \%, 5 \%$ and $1 \%$ level respectively;

standard errors in ( ).

Regarding interest rates, a rise in interest rates implies an increase in the financing cost of loans. In particular, small firms which needed money to survive the crisis could not afford the financing cost, and failed to return their earlier loans. In addition, exchange rates have a strong negative correlation with the default rate for particular types of firms. Thus, the depreciation of RMB had negative impacts on three types of industries: industries whose raw materials are imported; second, those industries which maintain a huge amount of foreign exchange liabilities; and, third, the tourism industry.

Interestingly, in our study we do not find a significant relationship between default rate and real estate price though, intuitively, one would expect this to be the case. The prolonged impacts on the default rate are captured by the lags i.e. DGDP(t-1): (0.09), DGDP(t-2): (0.10), RPI(t-4): (-0.07), DUNE(t-1): (1.12), DUNE(t-2): (0.83), DUNE(t-3): (0.82), DUNE(t-4): 
(0.95), DFIX(t-1): (-0.02), DFIX(t-2): (-0.03), M2(t-4): (-0.04), DINT(t-4): (-0.26), DEX(t-1): $(-1.18)$, and DEX(t-2): (-1.19). Moreover, the coefficient of the lagged default rate, $\mathrm{y}_{\mathrm{t}}(\mathrm{t}-1)$ : $(0.96)$ and $\mathrm{y}_{\mathrm{t}}(\mathrm{t}-3):(-0.66)$, are significant. This finding indicates that the expected default rate of banks in the past period would generate a prolonged impact on the NPLR in the current period. In other words, a one percentage point increase of the NPLR in the previous quarter will lead to a NPLR increase of 0.96 percentage points in the current quarter, which indicates that the impact of shocks are long-lasting. Because the signs of the coefficients of $y_{t}(t-1)$ and $y_{t}(t-$ 3) are different, it implies that the response of the banking system towards shocks is slow, possibly due to the time needed for implementing risk solutions. Meanwhile, this finding suggests that it is necessary for the regulators to launch a risk early warning system to identify the potential shocks, and the real shocks, at an early stage. This is because it is too late when the impact of the shock appears on the banks' balance sheet. The fact that negative autocorrelation of $\mathrm{y}_{\mathrm{t}}(\mathrm{t}-3)$ is different from the previous research (Shen and Feng, 2010) ${ }^{39}$ may be attributed to the differences in frequency of data. However, we posit that the quarterly data we employ is likely to be more informative. Given the autocorrelation of $y_{t}$, it is necessary to analyze the progress of the default rate over a time horizon that is longer than the duration of the designed shock in order to reflect the long-term impact of the shock.

In addition to the aforementioned analysis, we conduct impulse response analysis in order to simulate shocks to the macro-economy, and estimate the feedback from these shocks to the NPLR. We are also able to estimate whether the changes in the NPLR have a further impact on macroeconomic developments. In the VAR approach, because of the lag structure, a shock on 
one variable not only impacts the variable itself, but also affect all of the other endogenous variables. Therefore, the impulse response function is used to explore the effect of a one-time shock to one of the innovations on current and future values of the endogenous variables. Following the traditional VAR literature, the impulse response analysis is accomplished by means of the orthogonalised impulse responses with Cholesky decomposition. Our impulse response functions suggest that the default rate increases to 0.08 over three quarters, following unexpected shocks to GDP, and reverts to a lower level in the fourth quarter. Unexpected shocks in the RPI result in a decrease in the default rate, with an effect potentially lasting more than 25 quarters. The response to a positive shock on real estate prices is not obvious during the first four quarters, and the impulse response of $y_{t}$ climbs to a peak of 0.25 from the fifth period to the twentieth. This can provide an explanation for why we failed to find a significant coefficient for real estate price in the credit risk model, because the impact of shocks to house prices can only be observed after four quarters, while the model estimates the lag value of the macroeconomic dynamics for four periods. However, when there is an innovation shock of one standard error for the unemployment rate, fixed investment, money supply, interest rate and the exchange rate respectively, there are no significant changes in $y_{t}$.

\subsection{Scenario Analyses}

In the previous analysis we examined the relationships between the NPLR and key macroeconomic variables. In this section we aim to examine the response of the expected 
default rate to macroeconomic shocks, via simulations. To generate the future path of the expected default rate, our scenario analysis conducts a stress test on the banking system in China, with historical and hypothetical scenario methods. The historical scenario method provides limited insight since China has maintained high growth for over two decades without suffering severe shocks. Given this, we seek to gain insight by mimicking the effects of the Asian Financial Crisis in 1998, and the Argentinean Financial Crisis (1999-2002), using the parameter estimates for the Chinese economy derived in the previous subsection. On the other hand, as uncertainty is the nature of hypothetical scenarios, we assume the macro risk factors follow the normal distribution and choose the 1/10,1/25, and 1/100 quantiles as the shock values, reflecting a 10-year, 25-year, and 100-year shock. These changes are modelled to occur separately from 2012Q4 to 2013Q2, from the moderate situation to the severe case, and there is no further artificial shock introduced for the subsequent quarters. We conduct the following out-of-sample forecast by step-by-step method. In every forecasting period, the model is recalculated with the new available data of variables of scenarios and generates the forecasted value of financial stability indicator for the next period. Given the macroeconomic variables we have selected, we design four scenarios as follows: (i) The benchmark scenario, in which there is no shock; (ii) shocks via the business cycle, in which China's GDP growth rate slides to $7 \%, 6 \%$, and $5 \%$ respectively in each of the three consecutive quarters (starting from 2012Q4); (iii) a rise in the interest rate by 300,400 , and 500 basis points respectively in each of the three consecutive quarters starting from 2012Q4; (iv) rises in the exchange rate by 5\%, $10 \%$, and $15 \%$ respectively in each of the three consecutive quarters starting from 2012Q4. 
Since stress testing focuses on extreme, but plausible shocks, we have designed the scenarios with a feasible probability such that these changes in the macroeconomic variables can occur. Furthermore, these scenarios reflect extreme situations which can bring large losses to the banking system. In addition, we have designed a worsening trend for shocks, as economic stimulus policies may not be effective immediately. Then we simulate 2000 future paths and compute the expected default rates in 2013Q4 to construct a frequency distribution. With this frequency distribution, we can examine whether the banking system is stable within a certain confidence level, because the tails of the distributions provide insight into the extreme losses.

Table 6: Stress-Testing Results for Scenarios

\begin{tabular}{|c|c|c|c|c|c|c|c|c|}
\hline \multirow[t]{2}{*}{ Period } & \multicolumn{2}{|c|}{ Benchmark } & \multicolumn{2}{|c|}{ GDP Shock } & \multicolumn{2}{|c|}{ Interest Rate Shock } & \multicolumn{2}{|c|}{ Exchange Rate Shock } \\
\hline & $\mathrm{y}_{\mathrm{t}}$ & $\operatorname{NPLR}(\%)$ & $\mathrm{y}_{\mathrm{t}}$ & $\operatorname{NPLR}(\%)$ & $y_{t}$ & $\operatorname{NPLR}(\%)$ & $\mathrm{y}_{\mathrm{t}}$ & NPLR (\%) \\
\hline 2012 Q4 & 4.34 & 1.29 & 4.34 & 1.28 & 4.34 & 1.29 & 4.34 & 1.29 \\
\hline 2013 Q1 & 4.14 & 1.57 & 4.09 & 1.63 & 4.14 & 1.57 & 3.04 & 4.54 \\
\hline 2013 Q2 & 3.98 & 1.83 & 3.71 & 2.93 & 3.98 & 1.83 & 0.99 & 27.15 \\
\hline 2013 Q3 & 4.20 & 1.48 & 3.62 & 2.58 & 4.34 & 1.28 & 0.46 & 38.76 \\
\hline
\end{tabular}

The default rates in the following three periods after the shocks (2013Q1, 2013Q2, and 2013Q3) 
were computed with the macroeconomic risk (VAR) model on a step-by-step basis. The results of this are outlined in Table 6 . The following are noteworthy:

1. The benchmark scenario: As that there is no shock in this scenario, the default rates $\left(\mathrm{y}_{\mathrm{t}}\right)$ are stable at about 4.17. Consequently, the NPLR for the whole banking system peaks at $1.83 \%$, indicating very stable conditions for the banking system.

2. The GDP shock scenario: Following the shock, the default rates in this scenario respond strongly to the change in GDP growth and the unemployment rate. The NPLR rises to $2.93 \%$ in $2013 \mathrm{Q} 2$, and falls down to $2.58 \%$ in 2013Q3. Accordingly, the influence of this business cycle shock on financial stability is profound, which would lead to an increase in provision for bad loans, and a concurrent decrease in capital adequacy. Even though China's growth has all the hallmarks of a successful softlanding in the past three years, the banking system is still vulnerable in the face of such a GDP shock.

3. The interest rate shock scenario: In this scenario we found a limited response in the relationship between the default rate and changes in the interest rate with the NPLR being raised to $1.83 \%$ in 2013Q2. Subsequently the NPLR falls to $1.28 \%$ in 2013 Q3. This result suggests that the major clients of banks (big corporations and state-ownedenterprises) are not sensitive to the financing cost of debt.

4. The exchange rate shock scenario. Recall that some industries — such as those whose raw materials are imported, those which maintain a huge amount of foreign exchange 
liabilities, and the tourism industry — can be profoundly affected by exchange rate shocks. It is of particular note that the strongest influence occurs in the exchange rate shock scenario, since the NPLR rockets to $27.15 \%$ in 2013Q2, and keeps rising to a more severe $38.76 \%$ in 2013Q3. This will likely lead to significant losses for banks and indicates that China's government should be cautious in exchange rate reform.

Building on this, we generate a conditional probability distribution of losses based on the concept of value-at-risk. This process is as follows: first, as reported in Table 7, we compute the response of the default rate with macroeconomic credit risk model and the Monte Carlo simulation (computed 2000 times); secondly, corresponding default rates are used to assess loss distributions.

Table 7: Loss Distribution Scenarios, A Quarterly Horizon

\begin{tabular}{|c|c|c|c|c|c|c|c|c|}
\hline & \multicolumn{2}{|c|}{ Benchmark } & \multicolumn{2}{|c|}{ GDP Shock } & \multicolumn{2}{|c|}{ Interest Rate Shock } & \multicolumn{2}{|c|}{ Exchange Rate Shock } \\
\hline Confidence Level (\%) & $\mathrm{y}_{\mathrm{t}}$ & $\operatorname{NPLR}(\%)$ & $\mathrm{y}_{\mathrm{t}}$ & $\operatorname{NPLR}(\%)$ & $\mathrm{y}_{\mathrm{t}}$ & $\operatorname{NPLR}(\%)$ & $\mathrm{y}_{\mathrm{t}}$ & $\operatorname{NPLR}(\%)$ \\
\hline 80 & 4.35 & 1.28 & 3.65 & 2.53 & 4.42 & 1.18 & 1.37 & 20.14 \\
\hline 90 & 4.27 & 1.38 & 3.57 & 2.74 & 4.34 & 1.29 & 1.25 & 22.29 \\
\hline
\end{tabular}


These loss distributions, again, include a benchmark scenario and three stressed scenarios. Generally, the value-at-risk results show that for the confidence level of 99\%, the banking system in China is able to maintain the financial stability with an interest rate shock, with an acceptable NPLR of less than 2\%. According to 'the Core Indicators for the Risk Management of Commercial Banks' (China Banking Regulatory Commission 2005), this indicates that the current risk from interest rate changes is moderate for the banking system. However, for the GDP shock and exchange rate shock our results suggest that with an $80 \%$ confidence level the NPLR exceeds the $2 \%$ threshold in each case. Our study suggests that an exchange rate shock is likely to be profoundly damaging in terms of the NPLR, exceeding $20 \%$ at each confidence level tested. The results shown in Table 7 do not contradict the previous step-by-step forecasting methods, though there are some differences in magnitude which can be explained by the differences in the methodological approach used. Overall, however, we would assert that this triangulates our result.

\section{CONCLUSION}

This paper has developed a framework for macro stress-testing of credit risk for the banking 
system in China. This framework was used to measure the financial stability of the banking system in response to shocks in different macroeconomic variables. We utilized VAR models and analyzed eight macroeconomic variables, with the macroeconomic credit risk models successfully explaining the impact of severe macroeconomic shocks on the balance sheet of banks. The analysis suggests that there are some significant relationships between the default rates and macroeconomic factors, such as GDP growth, the unemployment rate, the interest rate, and the exchange rate, which are focal concerns for macro stress testing perspectives.

Macro stress-testing is used to assess the financial stability of the banking system. We combined the historical method and the hypothetical method to produce three stress scenarios with various artificial shocks including GDP growth shocks, interest rate shocks, and exchange rate shocks. Thereafter, the distribution of possible NPLRs, derived from the Monte Carlo method, was simulated, and the value-at-risk for credit risk was calculated. The results indicate that the banking system in China would be healthy in the case of interest rate shocks, but in the case of GDP growth and exchange rate shocks the NPLR of banks would climb beyond the limit of $2 \%$.

Although from a macro prudential perspective China emerged unscathed from the GFC, the Central Bank of China should learn the lessons of risk management from Western countries and encourage commercial banks to carry out both micro stress-testing and macro stress-testing under the framework of FSAP. For the policy makers, they should pay more attention to the stress testing results during the decision-making process, especially when formulating growth 
and exchange rate policies. In particular, the ongoing foreign exchange rate system reform is something that needs to be considered carefully so that China can avoid severe exchange rate shocks, which our study suggests would be extremely costly. Our results also provide helpful suggestions to policymakers in China in monetary policy formulation. The empirical results indicate that the interest rate and money supply have significant effects on the stability of the banking system in China. Therefore, applying the interest rate and the reserve requirement ratio is useful for China to achieve financial stability. In practice, when the economy slows, the policymaker could decrease the interest rate and the reserve requirement ratio to stimulate the economy. When the economy is booming, the policymaker could increase the interest rate and the reserve requirement ratio to suppress the economy and reserve certain capital buffer for potential shocks to banking sector.

\section{REFERENCES}

1. Tagkalakis, A. (2013). The effects of financial crisis on fiscal positions. European Journal of Political Economy, 29(29): 197-213.

2. Aboody, D., Hughes, J. S., Bugra Ozel, N. (2014). Corporate bond returns and the financial crisis. Journal of Banking \& Finance, 40: 42-53.

3. The notion of stress testing — which was originally developed in medicine (Missal, 1938) — has emerged as both an ex ante risk management tool for identifying vulnerability ahead an extreme shock, and a crisis management and resolution tool (Wong et al., 2010; 
Visco, 2011).

4. Missal, M. E. (1938). Exercise tests and the electrocardiograph in the study of angina pectoris. Annals of Internal Medicine, 11(11): 2018-2036.

5. Wong, J., Wong, T. C., Leung, P. (2010). Predicting banking distress in the EMEAP economies. Journal of Financial Stability, 6(3): 169-179.

6. Visco, I. (2011). Key issues for the success of macro prudential policies. Bank for International Settlement Working Paper, No.60.

7. Sorge, M. (2004). Stress-testing financial systems: an overview of current methodologies. Bank for International Settlement Working Paper, No.164.

8. Marcelo, A., Rodríguez, A., Trucharte, C. (2008). Stress tests and their contribution to financial stability. Journal of Banking Regulation, 9(2): 65-81.

9. Stulz, R. (2008). Risk management failures: What are they and when do they happen? Jou rnal of Applied Corporate Finance, 20(4): 39-48.

10. Huang, X., Zhou, H., Zhu, H. (2009). A framework for assessing the systemic risk of major financial institutions. Journal of Banking \& Finance, 33(11): 2036-2049.

11. Aizenman, J., Pasricha, G. K. (2012). Determinants of financial stress and recovery during the great recession. International Journal of Finance \& Economics, 17(4): 347-372.

12. Borio, C. (2006). Monetary and financial stability: here to stay? Journal of Banking and Finance, 30(12): 3407-3414. 
13. Borio, C., Drehmann, M., Tsatsaronis, K. (2012). Stress-testing macro stress testing: does it live up to expectations? Bank for International Settlements Working Paper, No.369.

14. Drehmann, M. (2005). A market based macro stress test for the corporate credit exposures of UK banks. BCBS seminar on Banking and Financial Stability: Workshop on Applied Banking Research.

15. Elsinger, H., Lehar, A., Summer, M. (2006). Risk assessment for banking system.Management Science, 52(9): 1301-1341.

16. Jacobson, T., Lindé, J., Roszbach, K. (2005).Exploring interactions between real activity and the financial stance. Journal of Financial Stability, 1(3): 308-341.

17. De Graeve, F., Kick, T., Koetter, M. (2008). Monetary policy and financial (in) stability: An integrated micro-macro approach. Journal of Financial Stability, 4(3): 205-231.

18. Pesaran, H. H., Schuermann, T., Smith, L. V. (2009).Forecasting economic and financial variables with global VARs. International Journal of Forecasting, 25(4): 642-675.

19. Aikman, D., Alessandri, P., Eklund, B., Gai, P., Kapadia, S., Martin, E., Willison, M. (2009).Funding liquidity risk in a quantitative model of systemic stability. EFA 2009 Bergen Meetings Paper.

20. Wilson, T. C. (1997a). Portfolio Credit Risk (I). Risk, 10(9): 111-17.

21. Wilson, T. C. (1997b). Portfolio Credit Risk (II). Risk, 10(10): 56-61.

22. Virolainen, K. (2004). Macro stress-testing with a macroeconomic credit risk model for 
Finland. Bank of Finland Discussion Paper, No.18/2004.

23. Sorge, M., Virolainen, K. (2006).A comparative analysis of macro stress-testing methodologies with application to Finland. Journal of financial stability, 2(2): 113-151.

24. Misina, M., Tessier, D., Dey, S. (2006). Stress testing the corporate loans portfolio of the Canadian banking sector. Bank of Canada Working Paper, No.2006-47.

25. Jiménez, G., Mencía, J. (2009).Modelling the distribution of credit losses with observable and latent factors. Journal of Empirical Finance, 16(2): 235-253.

26. Xu, M., Liu, X. (2008). Financial System Stability Assessment: based on the Comparison of macro stress testing method. Study of International Finance, 2: 39-42. (In Chinese).

27. Ren, Y., Sun, X. (2007). The application of stress testing of credit risk. Statistic and Decision, 7: 101-106. (In Chinese)

28. Chen, H., Wu, Z. (2004). The Vulnerability of Banking System. Journal of Quantitative \& Technical Economics, 4: 69-71. (In Chinese).

29. Boss, M. (2002). A macroeconomic credit risk model for stress testing the Austrian credit portfolio. Oesterreichische National Bank Financial Stability Report, 4: 64-82.

30. Wong, J., Choi, K. F., Fong, T. (2006). A framework for macro stress testing the credit ris k ofbanks in Hong Kong. Hong Kong Monetary Authority Quarterly Bulletin, December, $25-38$.

31. Bardsen, G., Lindquist, K. G., Tsomocos, D. P. (2006). Evaluation of macroeconomic 
models for financial stability analysis. Norges Bank Working Paper No. 2006/01.

32. Bunn, P., Cunningham, A., Drehmann, M. (2005). Stress testing as a tool for assessing systemic risk. Bank of England Financial Stability Review, 18: 116-126.

33. Pesaran, H. H., Schuermann, T., Treutler, B. J., Weiner, S. M. (2006). Macroeconomic dynamics and credit risk: a global perspective. Journal of Money Credit and Banking, 38(5): 1211-1261.

34. Alves, I. (2005).Sectoral fragility: factors and dynamics. Bank for International Settlement Working Paper No 22.

35. China Bank Regulatory Commission. (2005). The core indicators for the risk management of commercial banks. (In Chinese)

36. White, E. N. (2009). Lessons from the great American real estate boom and bust of the 1920s. National Bureau of Economic Research, Working Paper15573.

37. Posen, A. (2003). It takes more than a bubble to become Japan. Institute for International Economics Working Paper, No.3-9.

38. Lutkepohl, H (1993) Introduction to Multiple Time Series Analysis. Berlin: Springer.

39. Shen, Y., Feng, W. (2010). Empirical research of the macroeconomic variables and the credit risk of banks: based on the analysis of macro stress testing. Friend of Accounting, 22: 88-91. (In Chinese) 
APPENDIX: Lag Length Criteria

\begin{tabular}{|c|c|c|c|c|c|c|}
\hline Lag & $\log L$ & LR & FPE & AIC & $\mathrm{SC}$ & HQ \\
\hline 0 & -458.59 & NA & 0.005 & 20.33 & 20.69 & 20.46 \\
\hline 1 & -189.38 & 421.38 & $1.62 \mathrm{e}-06$ & 12.15 & 15.72 & 13.49 \\
\hline 2 & -105.09 & 98.94 & $2.12 \mathrm{e}-06$ & 12.00 & 18.80 & 14.55 \\
\hline 3 & 36.86 & 111.10 & $5.46 \mathrm{e}-07$ & 9.35 & 19.37 & 13.11 \\
\hline 4 & 580.04 & $212.55^{*}$ & $4.35 \mathrm{e}-14^{*}$ & $-10.74 *$ & $2.49 *$ & $-5.78 *$ \\
\hline \multicolumn{7}{|c|}{ * Indicates lag order selected by the criterion } \\
\hline \multicolumn{7}{|c|}{ LR: sequential modified LR test statistic (each test at 5\% level) } \\
\hline \multicolumn{7}{|c|}{ FPE: Final prediction error } \\
\hline \multicolumn{7}{|c|}{ AIC: Akaike information criterion } \\
\hline \multicolumn{7}{|c|}{ SC: Schwarz information criterion } \\
\hline
\end{tabular}

